\title{
Contribuição a avaliação do aprendizado nas plataformas digitais em Ensino à Distância
}

\author{
Ighor Opiliar Mendes Rimes ${ }^{1}$ \\ UERJ, Rio de Janeiro, RJ \\ Regina Serrão Lanzillotti ${ }^{2}$ \\ UERJ, Rio de Janeiro, RJ
}

\begin{abstract}
Resumo. A epidemia da COVID-19 impulsionou as plataformas virtuais para os professores impedidos de lecionar presencialmente. A Fundação CECIERJ oferece cursos remotos de aperfeiçoamento de professores desde o ano 2000. O foco deste artigo são os professores de Matemática oriundos da rede pública e privada do Estado do Rio de Janeiro. Dentre as plataformas do modelo remoto, optou-se em avaliar as atividades no "Google Classroom" e o "Google Forms". Esta validação contribui a reflexões dos gestores da Fundação CECIERJ quanto a planejamentos e o Teste de Hipóteses de Diferenças de Médias ao risco probabilístico de $5 \%$, permitiu verificar que não ocorreu discrepância no aproveitamento desses grupos, o que permite concluir que o plano de curso foi adequado e que venha a promover maior adesão, mesmo que por interesse própio.
\end{abstract}

Palavras-chave. Ensino à Distância, Teste de Hipótese, Plataformas digitais, Avaliação pedagógica

\section{Introdução}

A oferta de cursos para o aperfeiçoamento de professores por muitos anos eram praticamente todos em modelos de Latus Sensu ou Stricto Sensu. Segundo Destro (1995) [3], a educação continuada é definida como toda e qualquer atividade que tem o objetivo de provocar uma mudança de atitudes e/ou comportamento a partir da aquisição de novos conhecimentos, conceitos e atitudes. Assim, o conceito de aprendizagem não é, portanto restringido ao período escolar, começa na infância e segue por toda a vida (VALENTE, 2001) [7].

O afastamento dos concluintes em licenciatura das Instituições de Ensino Superior (IES) pós a conclusão dos cursos têm levado a não interação das práticas pedagógicas vigentes, consequentemente não se inteirando das novas metodologias inerentes ao Ensino à Distância (EAD) que surgiram durante seu tempo de prática docente, permanecendo com os conceitos didático obtidos na licenciatura. Hoje diversas instituições públicas têm oferecido cursos de extensão com oferta de disciplinas que vem trazer uma visão diferenciada e complementar daquelas vistas na graduação. Cabe ressaltar que a oferta nas diversas áreas do conhecimento vem sofrendo um aumento significativo. A geração de graduandos e graduados com a vivência "online" impulsionou a cursá-las para que atualizem e enriqueçam pedagogicamente o professor, ponto fundamental na atual conjuntura.

O problema advindo à COVID-19 resultou em medidas que vão desde suspensões das aulas sem interação por plataformas virtuais até a realização das ditas aulas remotas, o que veio acelerar o uso das tecnologias online tanto para o professor quanto para o aluno. Em Auckland, Nova Zelândia

\footnotetext{
1ighorimes@gmail.com

2 reginalanzillotti@gmail.com
} 
ocorreu uma ação efetiva para controle do Coronavírus, diminuindo a contaminação e permitindo o acompanhamento sistemático e efetivo de novos casos, viabilizando o retorno parcial das atividades escolares em maio de 2020 (ALVES, 2020) [1]. No Brasil, além da lentidão das tomadas de decisão para o controle da pandemia, o problema socioeconômico da maioria dos alunos e a limitação de verba das instituições de ensino retardou o desenvolvimento de aulas não-presenciais por meio das plataformas digitais. A pesquisa TIC domicílios (2019) [5] mostra que o acesso à internet das classes A, B, C, D e E apresentaram índices de 99\%, 95\%, 80\% e 50\%; respectivamente, o que leva a crer que não somente a escola passa por essas dificuldades, mas emergem excluídos no ensino remoto. A situação econômica da maioria dos discentes pertencentes ao grupo das classes C, D e E não tiveram condição de acesso aos meios digitais inerentes aos períodos emergenciais "online".

O modelo emergencial impulsionou a saída da zona de conforto do docente, pois muitos julgavam ser uma tarefa impossível lidar com este novo cenário. A redescoberta desta nova vertente didática gerou mais susceptibilidade a docência à distância, no sentido de lidar com os materiais e vídeos. É importante também ressaltar o carisma do docente no aprendizado quanto a interação com os alunos, que devem ser motivados no uso dos equipamentos digitais, pois se beneficiam na abertura de novos horizontes ao aprender.

Uma alternativa a esse novo modelo emergencial é apresentada pela Fundação Centro de Ciências do Estado do Rio de Janeiro - Fundação CECIERJ fundada em 2000, que tem missão de incentivar e promover a formação continuada dos professores no uso das ferramentas digitais, sobretudo durante a pandemia da COVID-19. A fundação possui 14 cursos de atualização para professores voltados as áreas de Ciências da Natureza, Ciências Humanas, Linguagens e Códigos, Matemática e Prática Docente. Na Matemática, ainda há resistência aos processos de atualização didática, sendo que a demanda tem fluxo contínuo de 500 cursistas.

\section{Objetivo}

Confrontar o aproveitamento dos cursistas da Fundação CECIERJ, professores de Matemática da rede pública e privada do Estado do Rio de Janeiro, segundo as plataformas "Google Classroom" e "Google Forms".

\section{Metodologia}

Raramente se consegue obter a distribuição da variável em apreço, se for um processo exaustivo, implicaria em ser dispendioso e os resultados poderiam retardar a informação. Assim, a solução é selecionar uma amostra e inferir propriedades para a população.

Segundo Morettin e Bussab (2010) [2], esta aplicação trata-se de duas amostras independentes de valores $\mathrm{x}_{1}, \ldots, \mathrm{x}_{n}$ e $\mathrm{y}_{1}, \ldots, \mathrm{y}_{m}$, selecionadas de duas populações $\mathrm{P}_{1}$ e $\mathrm{P}_{2}$, respectivamente. O interesse é comparar as médias dessas populações, isto é, se podem ser consideradas iguais ou não. No presente estudo considerou-se que as amostras foram advindas de distribuições normais, $\mathrm{P}_{1} \sim N\left(\mu_{1},\left(\sigma_{1}^{2}\right)\right)$ e $\mathrm{P}_{2} \sim N\left(\mu_{2},\left(\sigma_{2}^{2}\right)\right)$. Deseja-se testar a hipótese $\mathrm{H}_{0}: \mu_{1}=\mu_{2}$. Neste caso, cada amostra terá as medidas estatísticas média, $\bar{x}$ e $\bar{y}$, e variâncias estimadas $\left(\widehat{\sigma_{1}^{2}}\right.$ e $\left.\widehat{\sigma_{1}^{2}}\right)$. O objetivo do teste estatístico de hipóteses é fornecer uma metodologia que permita verificar se as estatísticas amostrais trazem evidências sobre uma hipótese formulada, hipótese nula $\left(\mathrm{H}_{0}\right)$, contrapondo-se a hipótese alternativa $\left(\mathrm{H}_{1}\right)$. Em função das hipóteses, pode-se cometer dois tipos de erros, o erro do tipo I e o erro do tipo II.

1. Erro do tipo I (região crítica): não há diferença de aproveitamento entre os dois grupos quando na realidade ocorre. 
2. Erro do tipo II: há diferença de aproveitamento entre os dois grupos quando na realidade não ocorre.

No teste de hipótese de diferença de médias atende-se os passos:

Passo 1. Fixe a hipótese nula $\left(\mathrm{H}_{0}\right)$ a ser testada e a hipótese alternativa $\left(\mathrm{H}_{1}\right)$.

Passo 2. Use a estatística teste inferencial (estimador) para decidir sobre a hipótese nula $\left(\mathrm{H}_{0}\right)$.

Passo 3. Fixe a região crítica segundo a probabilidade $\alpha$ de cometer o erro de tipo I, rejeitar a hipótese $\left(\mathrm{H}_{0}\right)$ quando verdadeira.

Passo 4. Use os valores amostrais para calcular a estatística teste inferencial.

Passo 5. Se o valor da estatística teste inferencial calculado estiver na região crítica, rejeita-se $\left(\mathrm{H}_{0}\right)$; caso contrário, aceita-se $\mathrm{H}_{0}$.

Sob a hipótese $\mathrm{H}_{0}: \mu_{1}=\mu_{2}$.

$$
\begin{gathered}
E(\bar{X}-\bar{Y})=0 \\
\operatorname{Var}(\bar{X}-\bar{Y})=\operatorname{Var}(\bar{X})+\operatorname{Var}(\bar{Y})=\frac{\sigma_{1}^{2}}{n}+\frac{\sigma_{2}^{2}}{m}
\end{gathered}
$$

se as variâncias populacionais forem conhecidas, a estatística teste (Z) para $\bar{X}-\bar{Y}$ tem distribuição normal

$$
Z=\frac{\bar{X}-\bar{Y}}{\sqrt{\frac{\sigma_{1}^{2}}{n}+\frac{\sigma_{2}^{2}}{m}}}
$$

Contudo, no presente trabalho, as variâncias não são conhecidas, devendo ser estimadas $\widehat{\left(\sigma_{1}^{2}\right.}$ e $\left.\widehat{\sigma_{2}^{2}}\right)$. Logo a estatística teste deve atender a distribuição $t$ de Student:

$$
T=\frac{\bar{X}-\bar{Y}}{\sqrt{\frac{\widehat{\sigma_{1}^{2}}}{n}+\frac{\widehat{\sigma_{2}^{2}}}{m}}}
$$

sendo que o número de graus de liberdade é dado por:

$$
v=\frac{(A+B)^{2}}{\frac{A^{2}}{n-1}+\frac{B^{2}}{m-1}}
$$

onde A e B são

$$
\begin{aligned}
& A=\frac{\widehat{\sigma_{1}^{2}}}{n} \\
& B=\frac{\widehat{\sigma_{1}^{2}}}{m} .
\end{aligned}
$$




\section{Resultados}

Este artigo utilizou o banco de dados construído pelos registros das notas das avaliações das atividades "Utilizando o Google Classroom" ("Google Classroom") e "Avaliação com o Google Forms" ("Google Forms") entre os cursistas/professores da rede pública e privada do Estado do Rio de Janeiro, alimentado pelos bolsistas de Iniciação à Docência na área de Matemática da Fundação CECIERJ. Cabe ressaltar que foi feito o pré-processamento, dos 84 e 37 cursistas que deveriam realizar a primeira atividade, apenas um foi eliminado em ambos regimes, público e privado, sendo que dos restantes, $32,14 \%$ e $32,43 \%$ não fizeram a segunda atividade, respectivamente. O interesse deste artigo é verificar se há diferença significativa entre as médias obtidas das avaliações segundo teste estatítistico de Diferença de Médias ao nível de significância de risco de 5\%, considerando-se que as amostras advêm de Distribuições de Probabilidades Normais.

A avaliação para ambas as redes deste curso busca mensurar a adaptabilidade às plataformas, sendo limitada até 15 pontos. Nas atividades "Google Classroom" e "Google Forms", a nota modal correspondeu ao valor máximo proposto na avaliação nas duas instituições. As frequências relativas ao desempenho na plataforma "Google Classroom" mostram que 86, 90\% dos cursistas que atuam em escolas públicas tiraram a nota máxima, e praticamente o mesmo percentual, 86, 48\%, os cursistas que atuam em escolas particulares. No caso do "Google Forms" estes indicativos foram 93, 10\% e 92, 00\% mantendo a mesma discriminação anterior. É importante ressaltar que o objetivo é auxiliar os cursistas em novas práticas "online" e não testar predominantemente a proeficiência, uma vez que os cursos têm característica de serem livres, pois deve-se ter o cuidado de incentivar, evitando a evasão.

A aferição da feição das distribuições de frequências foram diagnosticadas pelo Coeficiente de Variação, pois quando inferior a 30,00\% pode-se inferir que há homogeneidade dos valores próximos à média. Nesta avaliação, os cursistas profissionais públicos que atuaram na plataforma "Google Classroom" obtiveram média 14, 23 e Coeficiente de Variação 16,27\%, enquanto os profissionais do setor privado alcançaram média 14,35 e Coeficiente de Variação de $13,57 \%$. As notas padronizadas do grupo público desta atividade comparadas a média e expressas em unidades do Desvio Padrão apresentou $-3,99$ para a nota mínima e 0,33 para a máxima. Uma vez que a nota mínima padronizada foi aquém de três desvios padrões, esta nota pode ser considerada um "outlier" correspondendo a quatro cursistas. No caso do ensino particular, as notas extremas padronizadas foram -4,81 apenas para um aluno, e 0,33.

Procedimento análogo para a outra atividade, mostrou médias 14,78 e 14,84 e Coeficiente de Variação, 6,45\% e 3,75\% para os cursistas de instituições públicas e privadas. As estatísticas padronizadas das notas extremas dos profissionais de escolas públicas foram -5, 03 para dois cursistas e 0,28 , que podem ser confrontadas com os da particulares $-3,34$ para dois cursistas e 0,29. As notas padronizadas mostraram que a segunda atividade foi de melhor assimilação para os cursistas, uma vez que a vivência na primeira plataforma facilitou o aprendizado.

O Teste de Diferença de Médias necessita das variâncias amostrais para obter as variâncias estimadas populacionais $\left(\widehat{\sigma_{1}^{2}}\right.$ e $\left.\widehat{\sigma_{2}^{2}}\right)$. O teste bilateral t de Student para diferença de médias ao nível de significância de $5 \%$ (4) e o número de graus de liberdade (5), indica valor de $-0,31$ para a estatística teste. O intervalo de confiança dos percentis da Curva Normal estão limitados em $-2,02$ e 2,02, o que permite decidir que as médias podem ser consideradas estatisticamente iguais na aferição da plataforma "Google Classroom".

A estatística teste t de Student correspondeu a -0,38, que ao confrontar com o intervalo de confiança dos percentis da Curva Normal Padrão limitados a esquerda e a direita por -2,06 a 2,06, permitem inferir que as médias podem ser consideradas estatisticamente iguais. 


\section{Conclusões}

Os resultados convergiram para a missão da Fundação CECIERJ que é propiciar uma atualização nos métodos didáticos que acompanham a velocidade dos recursos tecnológicos utilizados no Ensino à Distância.

A estratégia em iniciar pela plataforma "Google Classroom" justifica-se pois grande parte das instituições de ensino a tem utilizado como plataforma inicial para os professores. As médias nesta avaliação foram menores do que as da plataforma "Google Forms", pois acredita-se que a adaptação digital adquirida na primeira atividade tornou o aprendizado facilitado para a segunda atividade. Os valores médios da avaliação podem ser considerados robustos, pois a variabilidade relativa da distribuição foi inferior a 16,27\%. O sucesso do aprimoramento dos cursistas de ambas as redes de ensino talvez possa ser limitado diante da dificuldade de acesso às tecnologias digitais. O resultado das atividades dos cursistas é uma importante ferramenta pedagógica como sucesso do processo do Ensino à Distância, talvez até mais expressivo que em processos presenciais.

A Fundação CECIERJ não só deve conhecer o perfil dos cursistas, mas intensificar o aprendizado às plataformas digitais que venham a atender as demandas referentes ao contexto pedagógico e gerenciamento das instituições de ensino, visando também ampliar a oferta para professores de outros estados que não possuam esse apoio.

No período inicial da pandemia os professores foram "jogados vivos no virtual", sem ter tido a oportunidade de aprender o uso das plataformas (OLIVEIRA et al, 2020) [6]. A situação agravouse ainda mais em relação aos professores considerados excluídos digitais, e muitos ainda aguardam a aula retornar presencialmente porque não conseguiram situar-se didaticamente nesta nova empreitada, em função da limitação de tempo para preparo de aula, pela sobrecarga da jornada de dois ou mais empregos que podem ser em plataformas diferentes, entre outros desafios (GOMES e ASSUNÇÃO, 2016) [4]. Apesar de haver discordância na utilização expressiva de recursos tecnológicos digitais no ensino presencial, há criticas que a velocidade do processo educacional é absurdamente mais lenta em comparação com outras atividades profissionais. A dinâmica do uso das ferramentas virtuais tende a impulsionar a adaptação ao novo modelo de ensinar, distanciandose do método pedagógico vigente. A flexibilização do instrumento de avaliação dos tutores pode contribuir para melhorar as práticas de gestão da Fundação CECIERJ.

A permanência dos cursistas na atividade atual ou em outras plataformas deve ser incentivada pelo contato pessoal via ambiente pedagógico virtual, mesmo que ocorra entraves durante a jornada de trabalho dos cursistas, o que evitará a evasão. A comparação dos valores extremos mínimos entre atividades diferenciadas é um indicador que talvez auxilie o planejamento pedagógico nas escolhas nas plataformas, e se for julgado necessário indicar no regime didático se há ou não a necessidade de pré-requisitos para evitar o desânimo na utilização das ferramentas digitais.

A gestão dos cursos EAD não tem sido feita em função dos indicadores referentes as questões direcionadas aos cursistas, o que pode levar a um direcionamento não realista da situação atual do curso. A aplicação de técnicas estatísticas inferenciais na época de planejamento curricular pode vir a intensificar maior interesse em função da própria divulgação dos ex-cursistas. Atender a necessidade de transgredir as práticas educacionais enraizadas no cotidiano, especialmente, neste cenário de mudanças instantâneas, entende-se ser a formação continuada um processo basilar para subsidiar as reflexões teórico-práticas dos professores e direcioná - los a novas formas de atuação [6].

\section{Agradecimentos}

Os autores agradecem a aquecência do diretor da Fundação CECIERJ que disponibilizou o acesso a plataforma "Programa de Formação Continuada de Professores", indispensável a efetivação deste artigo que avalia o aproveitamento nos cursos da plataforma "Google Classroom" e "Google 
Forms"

\section{Referências}

[1] Alves, L. Educação remota: Entre a ilusão e a realidade, Interfaces Científicas Educação, volume 8, páginas 348-365, 2020. DOI: 10.17564/2316-3828.2020v8n3p348-365.

[2] Bussab, W. de O. and Morettin, P. A. Estatística Básica, 6 ${ }^{a}$ edição. Saraiva, São Paulo, 2010.

[3] Destro, M. R. P. Educação Continuada: visão histórica e tentativa de contextualização, Caderno Cedes Educação Continuada, volume 36, São Paulo, 1995.

[4] Gomes, L. I. A. and Assunção, J. R. Educação à Distância: Uma estratégia de formação continuada no processo de aprimoramento profissional, $8^{o}$ Encontro Internacional de Formação de Professores, volume 8, número 1, 2016.

[5] Storino, F. Pesquisa sobre o uso das tecnologias de informação e comunicação nos domicílios brasileiros: TIC domicílios, 2019, $1^{\text {a }}$ edição, São Paulo, 2019, Disponível em: https://cetic.br/pt/publicacao/pesquisa-sobre-o-uso-das-tecnologias-de-informacao-ecomunicacao-nos-domicilios-brasileiros-tic-domicilios-2019/. Acesso em: 14 mar. 2021. ISBN 978-65-86949-22-3.

[6] Oliveira, S. da S., Silva, O. S. F. and Silva, M.J. de O. Educar na incerteza e na urgência: implicações do ensino remoto ao fazer docente e a reinvenção da sala de aula, Interfaces Científicas, volume 10, número 1, páginas 25-40, 2020. DOI: 10.17564/2316-3828.2020v10n1p2540 .

[7] Valente, J. A. Aprendizagem continuada ao longo da vida, Pátio Revista Pedagógica, volume 4, número 1, 2001. 